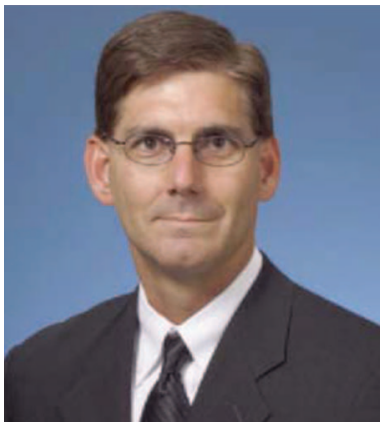

\section{The Importance of Science and Technology}

As the world economy is shaken by debt problems in both Europe and the United States, governments have been taking serious looks at cutting budgets. These budget considerations will only become more serious in the future, as the United States has committed to identifying, before the year is done, an additional 1.2 trillion dollars of government budget cuts over the next 10 years. The European debt crises are leading to similar large government budget cuts. Everything is game for cuts including entitlement programs, which have been immune for many years, but will have to be cut in the future to accommodate the aging of the population. My own military community, which has also been somewhat shielded from budget reductions in recent years, has been slated to take a 350 billion dollar cut over projected budgets in the next 10 years. My concern is that science and technology will suffer a disproportionate share of these budget cuts. Science and technology make an easy target for government policy makers, since frequently these fields are not seen to have an immediate effect on any individual's livelihood; however, science and technology certainly have a dramatic long-term effect on everyone's livelihood.

In many ways, science and technology drive the economy, albeit with a substantial time delay. According to the InterAcademy Council, wealthy industrialized nations typically spend between $1.5 \%$ and $3.8 \%$ of their GDP on research and development. In return, these nations have strong technology and service sectors. A simple example is the invention of the airplane, which led to an entire airline industry, with large company revenues that top 30 billion dollars and employ thousands of workers. In our own technical area, due to the invention of the laser, the market is predicted by Penwell's Steve Anderson (http://optics.org/news/2/1/18) to be in excess of 7 billion dollars in 2011. In my own laboratory, the invention of the Global Positioning System (GPS) has resulted in a huge industry. GPS devices are predicted by Reuters to be a 75 billion dollar industry by 2013. As big as these numbers are, they are dwarfed by the wealth created in the semiconductor and computer industries by the invention of the transistor and the integrated circuit. The businesses and jobs created by the Internet and personal electronics are expanding at explosive rates even as I write this. Science and technology literally create entire industries, and one result is jobs. The creation and maintenance of the associated jobs more than repays the initial investment in science and technology via more government tax revenue and less demand for entitlement expenditures.

Science and technology also secure our nations against national threats and terrorism. Night-vision technology enables our troops when fighting terrorist groups. GPS technology allows for precision strikes while protecting innocent civilians. Laser technology allows accurate monitoring of regions for weapons of mass destruction and is the future of directed energy weapons for missile defense and ship protection. Warfare has extended to the cyber domain, where there are now disciplines of warfighters who are trained to fight in cyberspace. Sensors, networks, materials, phenomenology, autonomy, and light/matter interactions are all key areas for the next generation of military technical capabilities.

Science and technology improve our overall health and wellbeing. Laser eye surgery restores sight without glasses. The genome project is resulting in disease analysis techniques and treatments that were never dreamed of ten years ago. Endoscopic and robotic surgeries, which minimize pain and recovery times, are now common. Seat belts, airbags, and crumple zones in cars lessen injuries and save lives. Computers, networks, and social media allow us to learn and digest information much faster than any time in history.

Now is not the time to cut science and technology budgets. Science and technology have many times played a key role at pivotal moments in history. The health of our nations depends on science and technology. The future of our children, including the education they receive, is highly dependent on science and technology. While the investments made by governments in research and development are usually small compared to the investments made by industry, the government emphasis is usually basic science. This basic science is the seed corn for the applied research component of science and technology and for our future economies. One might be tempted to eat the seed corn to alleviate immediate hunger, but that will only guarantee severe shortages later when there is no crop to harvest. If there is no basic research now, then there will not be new technologies and industries springing from applied research in the future. While most government members who make policies and budgets are not scientists or engineers, those of us who are should help them understand the importance of science and technology.

Ronald G. Driggers Editor 